\title{
Crystallization of Local Anesthetics When Mixed With Corticosteroid Solutions
}

\author{
Hyeoncheol Hwang, MD, Jihong Park, MD, Won Kyung Lee, MD, Woo Hyung Lee, MD, \\ Ja-Ho Leigh, MD, Jin Joo Lee, BS, Sun G. Chung, MD, PhD, Chaiyoung Lim, MD, \\ Sang Jun Park, MD, Keewon Kim, MD, MS \\ Department of Rehabilitation Medicine, Seoul National University Hospital, \\ Seoul National University College of Medicine, Seoul, Korea
}

Objective To evaluate at which $\mathrm{pH}$ level various local anesthetics precipitate, and to confirm which combination of corticosteroid and local anesthetic crystallizes.

Methods Each of ropivacaine- $\mathrm{HCl}$, bupivacaine- $\mathrm{HCl}$, and lidocaine- $\mathrm{HCl}$ was mixed with 4 different concentrations of $\mathrm{NaOH}$ solutions. Also, each of the three local anesthetics was mixed with the same volume of 3 corticosteroid solutions (triamcinolone acetonide, dexamethasone sodium phosphate, and betamethasone sodium phosphate). Precipitation of the local anesthetics (or not) was observed, by the naked eye and by microscope. The $\mathrm{pH}$ of each solution and the size of the precipitated crystal were measured.

Results Alkalinized with $\mathrm{NaOH}$ to a certain value of $\mathrm{pH}$, local anesthetics precipitated (ropivacaine $\mathrm{pH} 6.9$, bupivacaine $\mathrm{pH}$ 7.7, and lidocaine $\mathrm{pH}$ 12.9). Precipitation was observed as a cloudy appearance by the naked eye and as the aggregation of small particles $(<10 \mu \mathrm{m})$ by microscope. The amount of particles and aggregation increased with increased $\mathrm{pH}$. Mixed with betamethasone sodium phosphate, ropivacaine was precipitated in the form of numerous large crystals ( $>300 \mu \mathrm{m}, \mathrm{pH} 7.5)$. Ropivacaine with dexamethasone sodium phosphate also precipitated, but it was only observable by microscope (a few crystals of 10-100 $\mu \mathrm{m}, \mathrm{pH}$ 7.0). Bupivacaine with betamethasone sodium phosphate formed precipitates of non-aggregated smaller particles $(<10 \mu \mathrm{m}, \mathrm{pH} 7.7)$. Lidocaine mixed with corticosteroids did not precipitate.

Conclusion Ropivacaine and bupivacaine can precipitate by alkalinization at a physiological $\mathrm{pH}$, and therefore also produce crystals at a physiological $\mathrm{pH}$ when they are mixed with betamethasone sodium phosphate. Thus, the potential risk should be noted for their use in interventions, such as epidural steroid injections.

Keywords Crystallization, Local anesthetics, Corticosteroid, Alkalinization, Precipitation

Received June 15, 2015; Accepted July 20, 2015

Corresponding author: Keewon Kim

Department of Rehabilitation Medicine, Seoul National University College of Medicine, 101 Daehak-ro, Jongno-gu, Seoul 03080, Korea Tel: +82-2-2072-2619, Fax: +82-2-743-7473, E-mail: keewonkimm.d@gmail.com

() This is an open-access article distributed under the terms of the Creative Commons Attribution Non-Commercial License (http://creativecommons.org/ licenses/by-nc/4.0) which permits unrestricted noncommercial use, distribution, and reproduction in any medium, provided the original work is properly cited. Copyright $\odot 2016$ by Korean Academy of Rehabilitation Medicine 


\section{INTRODUCTION}

The particle size and aggregation pattern of corticosteroids used in epidural injection are widely known to clinicians. Dexamethasone sodium phosphate does not contain particles or aggregate significantly. In contrast, triamcinolone acetonide has particles of $0.5-110 \mu \mathrm{m}$ in size and develops evident aggregation [1-3]. In cases of an unintended intra-arterial injection of the particulate corticosteroid, the particles or aggregates much larger than blood cells can cause embolic brain or spinal cord infarction; clinicians who conduct spinal intervention are ever concerned about this issue [4-6].

However, the crystal formation of local anesthetics used in epidural injection has not been well studied. Local anesthetics are weak bases (e.g., lidocaine, bupivacaine, and ropivacaine have dissociation constants [pKa] of 7.7, 8.1, and 8.1, respectively), and most consist of an aromatic ring connected to an amine group with an amide bond, and have poor solubility in water $[7,8]$. Such properties suggest that they may precipitate in basic condition. Many commercial corticosteroid solutions include weak bases such as dexamethasone sodium phosphate and betamethasone sodium phosphate. As such, local anesthetics may flocculate when they are mixed with commercial corticosteroids. In our experience, precipitation was clearly observed in selective combinations of local anesthetic and corticosteroid (Fig. 1). Such flocculation of injectate represents a potential hazard, in vivo. Thus, in this study, we aimed to test at which $\mathrm{pH}$ level various local anesthetic solutions produce crystal, and to confirm which combination of corticosteroid and local anesthetic yields crystal.

\section{MATERIALS AND METHODS}

\section{Materials}

'Ropivacaine-HCl 0.75\%' (Hanlim Pharm. Co. Ltd., Seoul, Korea), 'bupivacaine-HCl injection 0.5\%' (Myungmoon Pharm. Co. Ltd., Bucheon, Korea), and 'lidocaine$\mathrm{HCl}$ injection 1\%' (Daihan Pharm. Co. Ltd., Seoul, Korea) were the local anesthetics used. To evaluate the crystal formation of the local anesthetics in mixture with corticosteroids, 'triamcinolone acetonide $40 \mathrm{mg} / \mathrm{mL}$ ' (Shinpoong Pharm. Co. Ltd., Seoul, Korea), 'dexamethasone sodium phosphate $5 \mathrm{mg} / \mathrm{mL}$ ' (Daewon Pharm. Co. Ltd., Seoul, Korea), and 'betamethasone sodium phosphate 5.2 $\mathrm{mg} / \mathrm{mL}$ ' (Daewon Pharm. Co. Ltd.) were used. To observe at which $\mathrm{pH}$ condition crystals of the local anesthetics are formed, sodium hydroxide $(\mathrm{NaOH})$ solutions at 4 different concentrations (1:1, 1:10, 1:100, and 1:1,000 dilutions of $0.1 \mathrm{M} \mathrm{NaOH}$ solution) were mixed with the local anesthetics. Insoluble crystal formation was confirmed by light microscopy (CX40-12J02; Olympus, Tokyo, Japan). The $\mathrm{pH}$ of the solution was measured by $\mathrm{pH} / \mathrm{mV} /$ temperature meter (XL15; Fisher Scientific, Pittsburgh, PA, USA).

\section{Methods}

The $p H$ and particle size of each local anesthetic and corticosteroid

The default $\mathrm{pH}$ of $4 \mathrm{~mL}$ of each of the 3 commercial local anesthetics (ropivacaine- $\mathrm{HCl}$, bupivacaine- $\mathrm{HCl}$, and lidocaine- $\mathrm{HCl}$ ) and 3 corticosteroids (triamcinolone
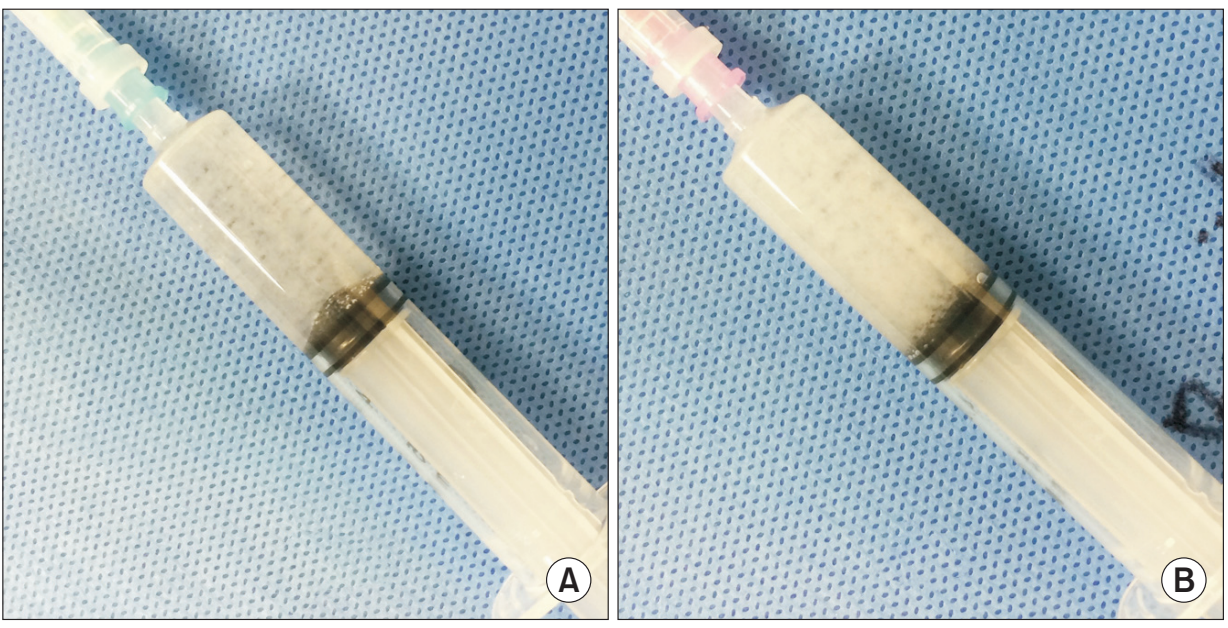

Fig. 1. Precipitation is observed as a cloudy appearance, when some local anesthetics are mixed with betamethasone sodium phosphate solution. (A) Ropivacaine$\mathrm{HCl}+$ betamethasone sodium phosphate. (B) Bupivacaine-HCl +betamethasone sodium phosphate. 
acetonide, dexamethasone sodium phosphate, and betamethasone sodium phosphate) was measured using a $\mathrm{pH}$ meter. The existence of particles of the local anesthetic or corticosteroid was evaluated by light microscopy.

\section{Precipitation of the local anesthetics in various $\mathrm{pH}$ con- ditions}

Two milliliters of local anesthetic solution (ropivacaine$\mathrm{HCl}$, bupivacaine- $\mathrm{HCl}$, or the lidocaine- $\mathrm{HCl}$ ) was mixed with $2 \mathrm{~mL}$ of $\mathrm{NaOH}$ solution at 4 different concentrations (1:1, 1:10, 1:100, and 1:1,000 diluted $\mathrm{NaOH}$ solutions). The $\mathrm{pH}$ of each mixture was measured using a $\mathrm{pH} / \mathrm{mV} /$ temperature meter. Irrespective of insoluble crystal formation, each mixed solution was observed with the light microscope and images were acquired. If crystals were observed on the microscope, the crystals were measured.

Insoluble crystal formation of local anesthetics in mixture with various corticosteroids

Two milliliters of local anesthetic solution (ropivacaine$\mathrm{HCl}$, bupivacaine- $\mathrm{HCl}$, or the lidocaine- $\mathrm{HCl}$ ) was mixed with $2 \mathrm{~mL}$ of corticosteroid solution (triamcinolone acetonide $80.0 \mathrm{mg}$, dexamethasone sodium phosphate 10.0 $\mathrm{mg}$, or betamethasone sodium phosphate $10.4 \mathrm{mg}$ solutions). $\mathrm{pH}$ measurement and the microscopic observation were conducted for each mixture. In case of crystal formation, the crystals were measured.

\section{RESULTS}

The $\mathrm{pH}$ and particle size of each local anesthetic and corticosteroid

We tested the $\mathrm{pH}$ of the 3 local anesthetics under examination; all of the local anesthetics- $\mathrm{HCl}$ solutions were weakly acidic. Ropivacaine solution was most acidic, $\mathrm{pH}$ 6.2, and bupivacaine solution followed at $\mathrm{pH}$ 6.4. The $\mathrm{pH}$ of the lidocaine solution was 6.7.

We also tested the $\mathrm{pH}$ of the corticosteroids under examination. Triamcinolone acetonide was the only acidic corticosteroid solution ( $\mathrm{pH}$ 6.1). Betamethasone sodium phosphate was most basic ( $\mathrm{pH}$ 8.8), and dexamethasone sodium phosphate was less basic ( $\mathrm{pH}$ 7.7) (Table 1).

No identifiable particles were observed in unmixed solutions of dexamethasone, betamethasone, ropivacaine, bupivacaine, or lidocaine. Triamcinolone acetonide solution contained particles of several micrometers in size
Table 1. The pH of commercial local anesthetics and corticosteroids

\begin{tabular}{|c|c|c|}
\hline Category & Product name & pH \\
\hline \multirow[t]{3}{*}{ Local anesthetics } & Ropivacaine-HCl $0.75 \%$ & 6.2 \\
\hline & Bupivacaine- $\mathrm{HCl} 0.5 \%$ & 6.4 \\
\hline & Lidocaine-HCl 1\% & 6.7 \\
\hline \multirow[t]{3}{*}{ Corticosteroid } & $\begin{array}{l}\text { Triamcinolone acetonide } \\
40 \mathrm{mg} / \mathrm{mL}\end{array}$ & 6.1 \\
\hline & $\begin{array}{l}\text { Dexamethasone sodium } \\
\text { phosphate } 5 \mathrm{mg} / \mathrm{mL}\end{array}$ & 7.7 \\
\hline & $\begin{array}{l}\text { Betamethasone sodium } \\
\text { phosphate } 5.2 \mathrm{mg} / \mathrm{mL}\end{array}$ & 8.8 \\
\hline
\end{tabular}

that formed aggregates of hundreds of micrometers in size.

Precipitation of local anesthetics in various $\mathrm{pH}$ conditions

Ropivacaine- $\mathrm{HCl}$ and bupivacaine- $\mathrm{HCl}$ showed no precipitation that could be seen by the naked eye or by microscope, when they were mixed with the 1:1,000 NaOH solution (Fig. 2A, E). The $\mathrm{pH}$ of the mixtures were 6.8 and 7.5 , respectively. In the mixtures with $1: 100,1: 10$, or $1: 1$ $\mathrm{NaOH}$ solutions ( $\mathrm{pH} 6.9,12.1$, and 12.8, respectively), ropivacaine- $\mathrm{HCl}$ produced insoluble particles and it was observed as a cloudy appearance by the naked eye. The particles were less than a few micrometers in size, but aggregations were found to be larger than hundreds of micrometers in size in the mixtures with 1:10 or 1:1 NaOH solution. The aggregation was larger in more basic conditions, so much so that the size of the aggregate ranged beyond $500 \mu \mathrm{m}$ at $\mathrm{pH} 12.8$ (Fig. 2B-D).

Similarly, bupivacaine- $\mathrm{HCl}$ produced insoluble particles in mixtures with $1: 100,1: 10$, or $1: 1 \mathrm{NaOH}$ solution $(\mathrm{pH}$ $7.7,12.2$, and 12.9 , respectively), and it looked cloudy to the naked eye. The particles found were smaller than a few micrometers in size. In the mixture with 1:1 NaOH solution, however, aggregates were larger than hundreds of micrometers (Fig. 2F-H).

Lidocaine- $\mathrm{HCl}$ showed no precipitation when it was mixed with 1:10 $\mathrm{NaOH}$ solution or less basic solutions (i.e., when the $\mathrm{pH}$ was 11.9 or less in the mixture) (Fig. 2I$\mathrm{K})$. In the mixture with the 1:1 $\mathrm{NaOH}$ solution, lidocaine$\mathrm{HCl}$ produced insoluble crystals ( $\mathrm{pH}$ 12.9) (Fig. 2L). The crystal size was often seen to be larger than $400 \mu \mathrm{m}$, but was fragile. The precipitation was also visible to the na- 


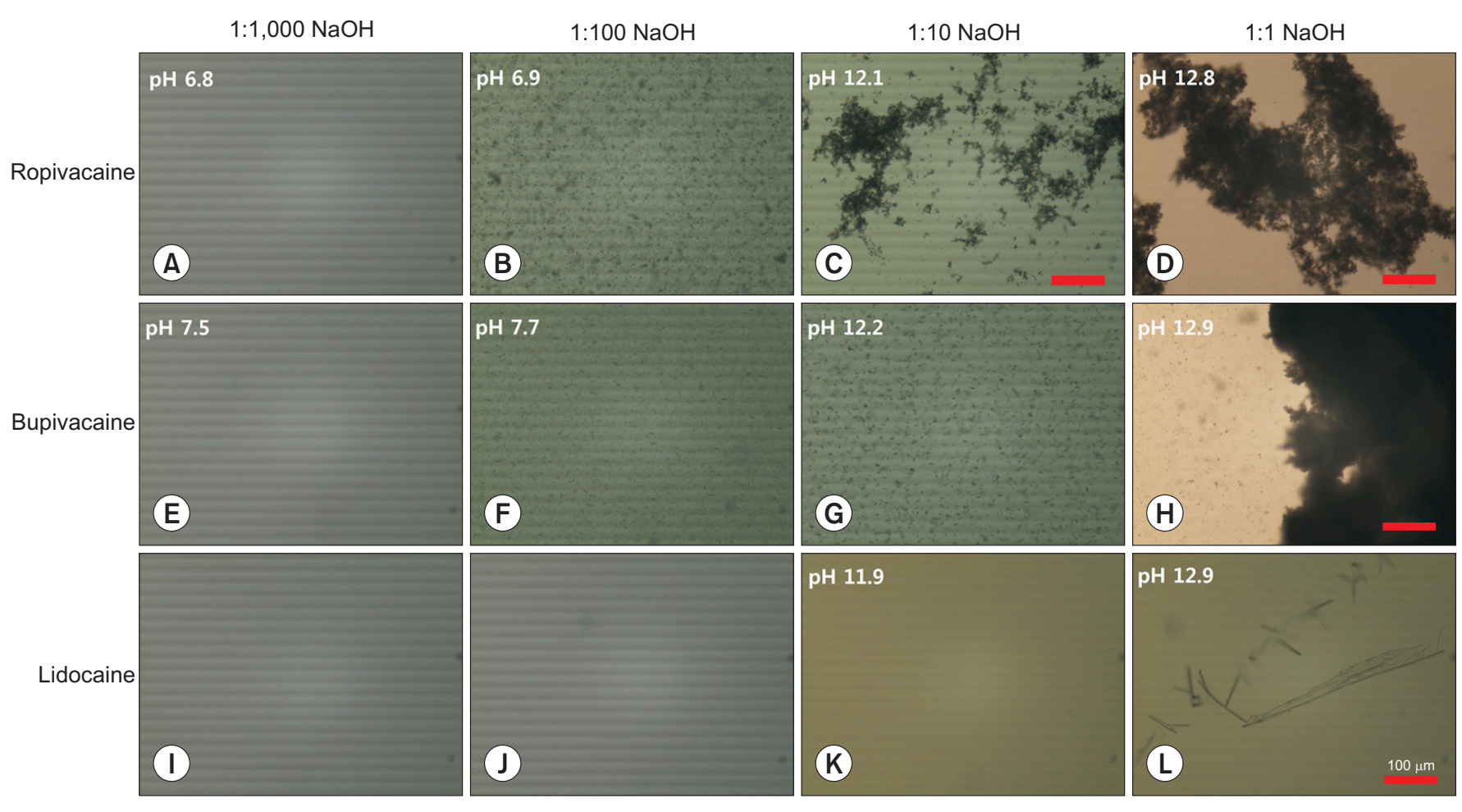

Fig. 2. Microscopy imaging of precipitation of local anesthetics in variable $\mathrm{pH}$ conditions $(100 \times)$; the scale bar indicates $100 \mu \mathrm{m}$. (A-D) Ropivacaine precipitated in solutions of $\mathrm{pH} 6.9$ or higher. Higher precipitation and aggregation were observed at higher $\mathrm{pH}$. (E-H) Bupivacaine began to produce insoluble particles at $\mathrm{pH} 7.7$, and (I-L) lidocaine developed crystals at $\mathrm{pH} 12.9$.

ked eye, in the form of a cloudy appearance.

Insoluble crystal formation of local anesthetics in mixture with various corticosteroids

Any of the 3 tested local anesthetics (ropivacaine, bupivacaine, and lidocaine), when mixed with triamcinolone acetate, were weakly acidic (pH 6.1, 6.3, and 6.5, respectively). Additional crystals were not observed apart from the triamcinolone particle itself.

Ropivacaine- $\mathrm{HCl}$ mixed with dexamethasone sodium phosphate, was $\mathrm{pH}$ 7.0, and no precipitation was observed to the naked eye. However, a few rod-shaped crystals, $10-100 \mu \mathrm{m}$ in size, were observed by microscopy. The mixture of ropivacaine- $\mathrm{HCl}$ and betamethasone sodium phosphate was weakly basic ( $\mathrm{pH}$ 7.5). The solution looked cloudy to the naked eye, containing visible precipitations. With the microscope, this solution showed many more and larger $(>300 \mu \mathrm{m})$ crystals than the mixed solution of ropivacaine and dexamethasone.

Bupivacaine- $\mathrm{HCl}$ rarely formed crystals when mixed with dexamethasone sodium phosphate ( $\mathrm{pH}$ 7.3). It did however develop numerous round, insoluble particles, a few micrometers in size without obvious aggregation, in the mixture solution with betamethasone sodium phosphate ( $\mathrm{pH}$ 7.7), appearing cloudy macroscopically.

Lidocaine- $\mathrm{HCl}$ did not precipitate in mixture with either dexamethasone or betamethasone ( $\mathrm{pH} 7.2$ and 7.7, respectively).

All microscopic analysis of mixed solutions of local anesthetics and corticosteroids are represented in Fig. 3.

\section{DISCUSSION}

The commercially used local anesthetics are maintained in acidic conditions (for example, ropivacaine$\mathrm{HCl} \mathrm{pH}$ 6.2, bupivacaine- $\mathrm{HCl} \mathrm{pH}$ 6.4, and lidocaine- $\mathrm{HCl}$ $\mathrm{pH}$ 6.7). When the $\mathrm{pH}$ of the solution increased to a certain value (ropivacaine $\mathrm{pH}$ 6.9, bupivacaine $\mathrm{pH}$ 7.7, and lidocaine $\mathrm{pH}$ 12.9), precipitation of the local anesthetics occurred, and it could be observed with the naked eye or by microscope. This precipitation and aggregation increased with higher $\mathrm{pH}$. 


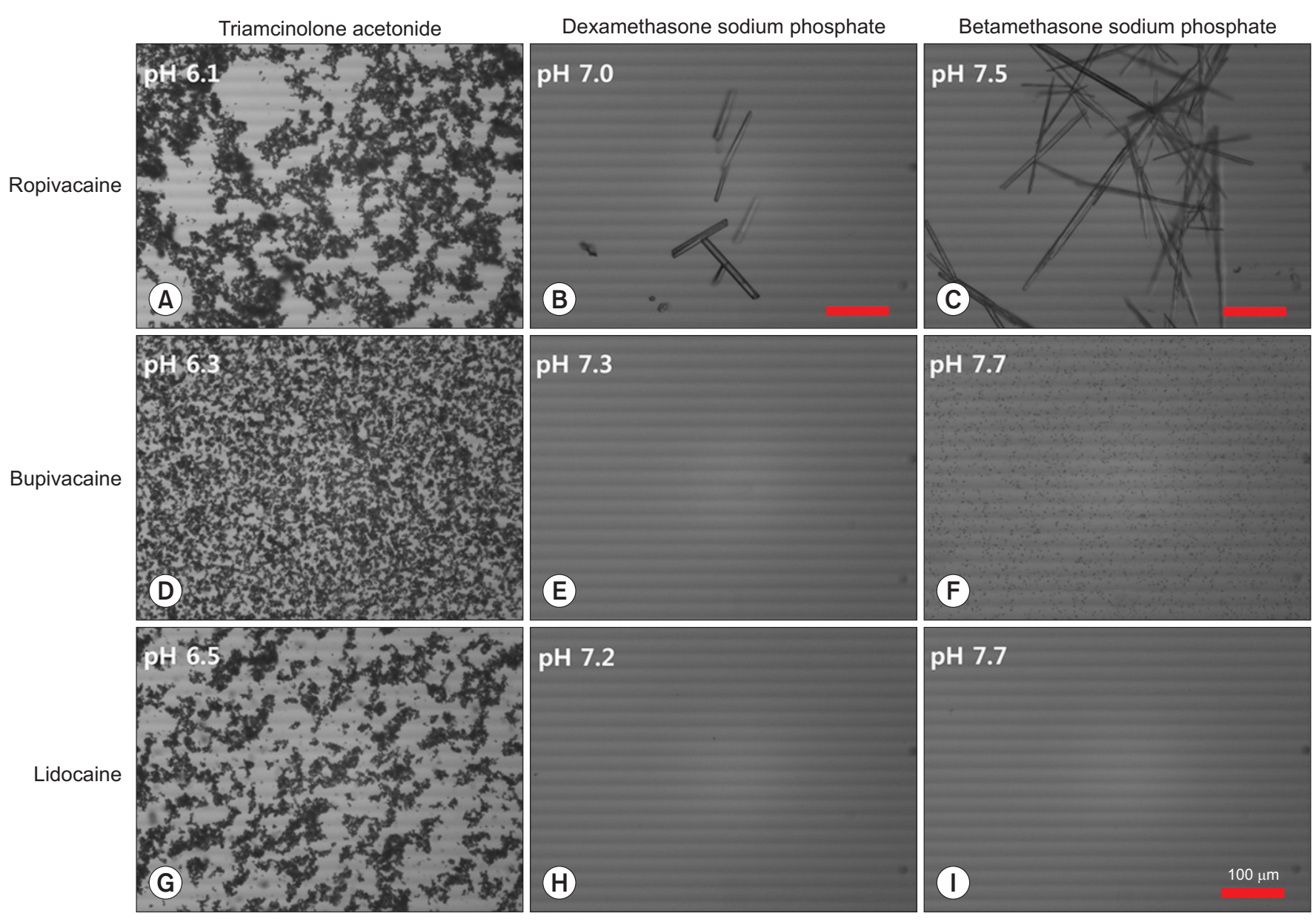

Fig. 3. Microscopy imaging of local anesthetics mixed with corticosteroid solutions (100x); the scale bar indicates $100 \mu \mathrm{m}$. Ropivacaine developed crystals in the mixed solution with either dexamethasone sodium phosphate (B) or betamethasone sodium phosphate (C). Many more and larger crystals were created at higher $\mathrm{pH}$ in solution with betamethasone, compared to when in solution with dexamethasone ( $\mathrm{pH} 7.5$ and $\mathrm{pH}$ 7.0, respectively). Bupivacaine precipitated in solution with betamethasone sodium phosphate (F, pH 7.7), but not in solution with dexamethasone sodium phosphate (E, pH 7.3). Lidocaine did not create any precipitate (H, I). Triamcinolone acetate did not induce precipitation of any local anesthetics tested, but the particles of triamcinolone itself were observed (A, D, G).

When ropivacaine- $\mathrm{HCl}$ was mixed with the same volume of basic corticosteroid solution-dexamethasone sodium phosphate ( $\mathrm{pH} 7.7$ ) and betamethasone sodium phosphate ( $\mathrm{pH} 8.8)$, ropivacaine became alkalinized (pH 7.0 and 7.5, respectively), and precipitation was observed; a greater number of larger crystals were observed in the betamethasone mixture when compared to those formed in the dexamethasone mixture. Among the mixed solutions of bupivacaine with the same volume of corticosteroid, only betamethasone sodium phosphate solution induced observable precipitation ( $\mathrm{pH}$ 7.7). No flocculation was observed in the solutions of lidocaine mixed with dexamethasone or betamethasone sodium phosphate.

These results are in close agreement with earlier studies that demonstrated ropivacaine and bupivacaine precipitation when they are alkalinized to physiologic $\mathrm{pH}$ with sodium bicarbonate, and lidocaine does not [9-12]. However, this phenomenon has not been emphasized in clinical journals or widely appreciated by physicians. Moreover, this is the first report that shows local anesthetics can precipitate when mixed with basic corticosteroid solutions that are widely used in clinical practice.

The mechanism by which this precipitation of local anesthetics occurs can be explained. Since the ratio of ionized to neutral base follows the Henderson-Hassel- 
balch equation ( $\mathrm{pH}=\mathrm{pKa}+\log$ [unionized form]/[ionized form]), the proportion of the unionized base form of a local anesthetic increases with alkalinization. Precipitation increases with alkalinization because these unionized forms tends to be relatively insoluble in water [7].

In our microscopic observations, precipitation patterns of local anesthetics were different depending on the base used ( $\mathrm{NaOH}$ vs. corticosteroid sodium phosphate). In mixtures with $\mathrm{NaOH}$ solution, large aggregates $(>100$ $\mu \mathrm{m})$ of small particles $(<10 \mu \mathrm{m})$ were formed. In contrast, large crystals $(>100 \mu \mathrm{m})$ could be generated in the mixed solutions with corticosteroids. In the literature, local anesthetics are known to have crystal polymorphisms with different thermodynamic stabilities [13]. One reason for the different precipitation patterns is thought to be the difference in the reaction rate. The low initial $\mathrm{pH}$ difference between the local anesthetic and corticosteroid solution may mean that the reaction rate is (relatively speaking) slow enough to develop large crystals. The larger molecules of corticosteroids could also contribute to the crystal formation as roles of condensation nuclei.

The flocculation may reduce the bioavailability of local anesthetics in vivo, but additional adverse effects or influences on the efficacy of corticosteroids are not well known. The size of crystals or aggregations of local anesthetics can be more than 10 times the size of red blood cells in vitro. If the precipitate is not broken into smaller pieces within the blood vessels, it may cause embolization. However, in vivo conditions differ from in vitro, in terms of $\mathrm{pH}$, buffers, and temperature. The clinical consequences of crystalized local anesthetics cannot be assumed based on the results of this study.

Nonetheless, precipitates of local anesthetics may sustain in vivo. The results of the current study were obtained at room temperature $\left(25^{\circ} \mathrm{C}\right)$; when the mixed solutions containing crystals were warmed to $40^{\circ} \mathrm{C}$, flocculation was not obviously changed (data not shown). This is in agreement with a previous study that examined the effect of temperature on precipitation of local anesthetics [14]. We also tested if the crystals could be dissolved with acidification by adding $\mathrm{HCl}$. Precipitates were confirmed to break down in strong acid ( $\mathrm{pH}$ 1.0), so it was inferred to be dissolved in a certain acidity. However, we observed that the flocculation of ropivacaine remained until pH 6.9. In our anecdotal experience, independent of the current study, crystalized ropivacaine mixed with betametha- sone was maintained within the muscle tissue after the injection (Supplementary Fig. 1). However, we still cannot be sure whether the crystals would dissolve, or not, in blood. Further research is warranted to assess the clinical significance and possible dangers of the crystallization of local anesthetics.

From the results of this study, there are a few areas for consideration in clinical practice. During last few years, ropivacaine- $\mathrm{HCl}$ has been more widely used than bupivacaine- $\mathrm{HCl}$ because of its reduced neurotoxicity and cardiovascular toxicity [15]. However, ropivacaine may require more watchful concern in terms of precipitation in mixture with basic corticosteroid solutions. Likewise, prudence is needed in the use of the corticosteroid, betamethasone sodium phosphate, when combined with local anesthetics. Betamethasone sodium phosphate is being increasingly used instead of triamcinolone acetate because triamcinolone is no longer recommended for epidural injections. However, in our study betamethasone sodium phosphate showed the strongest propensity for precipitating local anesthetics. If physicians are concerned about the potential hazard of precipitation of local anesthetics mixed with corticosteroid solution, the risk can be circumvented by sequential injection of local anesthetics before (or after) corticosteroid or by injecting only corticosteroid without the local anesthetic.

In conclusion, bupivacaine, ropivacaine, and lidocaine produce flocculation by alkalinization; ropivacaine and bupivacaine can precipitate even in physiological $\mathrm{pH}$. Furthermore, ropivacaine and bupivacaine also produce crystals when they are mixed with basic corticosteroid solutions, particularly with betamethasone sodium phosphate. These potential risks should be noted prior to musculoskeletal interventions, such as epidural steroid injection, using corticosteroids and local anesthetics.

\section{CONFLICT OF INTEREST}

No potential conflict of interest relevant to this article was reported.

\section{SUPPLEMENTARY MATERIALS}

Supplementary materials can be found via http:// dx.doi.org/10.5535/arm.2016.40.1.21. Fig. S1. The ultrasonic images of an occipital nerve block using be- 
tamethasone sodium phosphate and ropivacaine- $\mathrm{HCl}$ (A, before injection; B, after injection; white arrows, the needle). Crystallized ropivacaine remained in the muscle tissue without dissolution after the injection (white arrow heads).

\section{REFERENCES}

1. Derby R, Lee SH, Date ES, Lee JH, Lee CH. Size and aggregation of corticosteroids used for epidural injections. Pain Med 2008;9:227-34.

2. MacMahon PJ, Shelly MJ, Scholz D, Eustace SJ, Kavanagh EC. Injectable corticosteroid preparations: an embolic risk assessment by static and dynamic microscopic analysis. AJNR Am J Neuroradiol 2011;32:18305.

3. Benzon HT, Chew TL, McCarthy RJ, Benzon HA, Walega DR. Comparison of the particle sizes of different steroids and the effect of dilution: a review of the relative neurotoxicities of the steroids. Anesthesiology 2007;106:331-8.

4. Gharibo C, Koo C, Chung J, Moroz A. Epidural steroid injections: an update on mechanisms of injury and safety. Tech Reg Anesth Pain Manag 2009;13:266-71.

5. Manchikanti L, Falco FJ, Benyamin RM, Gharibo CG, Candido KD, Hirsch JA. Epidural steroid injections safety recommendations by the Multi-Society Pain Workgroup (MPW): more regulations without evidence or clarification. Pain Physician 2014;17:E57588.
6. Rodriguez RW. How safe is epidural steroid injection? Examining drug-related factors. Pract Pain Manag 2014;14:31-5.

7. McLure HA, Rubin AP. Review of local anaesthetic agents. Minerva Anestesiol 2005;71:59-74.

8. Brandis K. Alkalinisation of local anaesthetic solutions. Aust Prescr 2011;34:173-5.

9. Milner QJ, Guard BC, Allen JG. Alkalinization of amide local anaesthetics by addition of $1 \%$ sodium bicarbonate solution. Eur J Anaesthesiol 2000;17:38-42.

10. Chassard D, Berrada K, Bouletreau P. Alkalinization of local anesthetics: theoretically justified but clinically useless. Can J Anaesth 1996;43:384-93.

11. Peterfreund RA, Datta S, Ostheimer GW. pH adjustment of local anesthetic solutions with sodium bicarbonate: laboratory evaluation of alkalinization and precipitation. Reg Anesth 1989;14:265-70.

12. Fulling PD, Peterfreund RA. Alkalinization and precipitation characteristics of $0.2 \%$ ropivacaine. Reg Anesth Pain Med 2000;25:518-21.

13. Schmidt AC. The role of molecular structure in the crystal polymorphism of local anesthetic drugs: crystal polymorphism of local anesthetic drugs, part X. Pharm Res 2005;22:2121-33.

14. Koitabashi T, Sekiguchi H, Miyao H, Kawasaki J, Kawazoe T. Precipitation of $\mathrm{pH}$-adjusted local anesthetics with sodium bicarbonate. Masui 1995;44:15-20.

15. Hansen TG. Ropivacaine: a pharmacological review. Expert Rev Neurother 2004;4:781-91. 


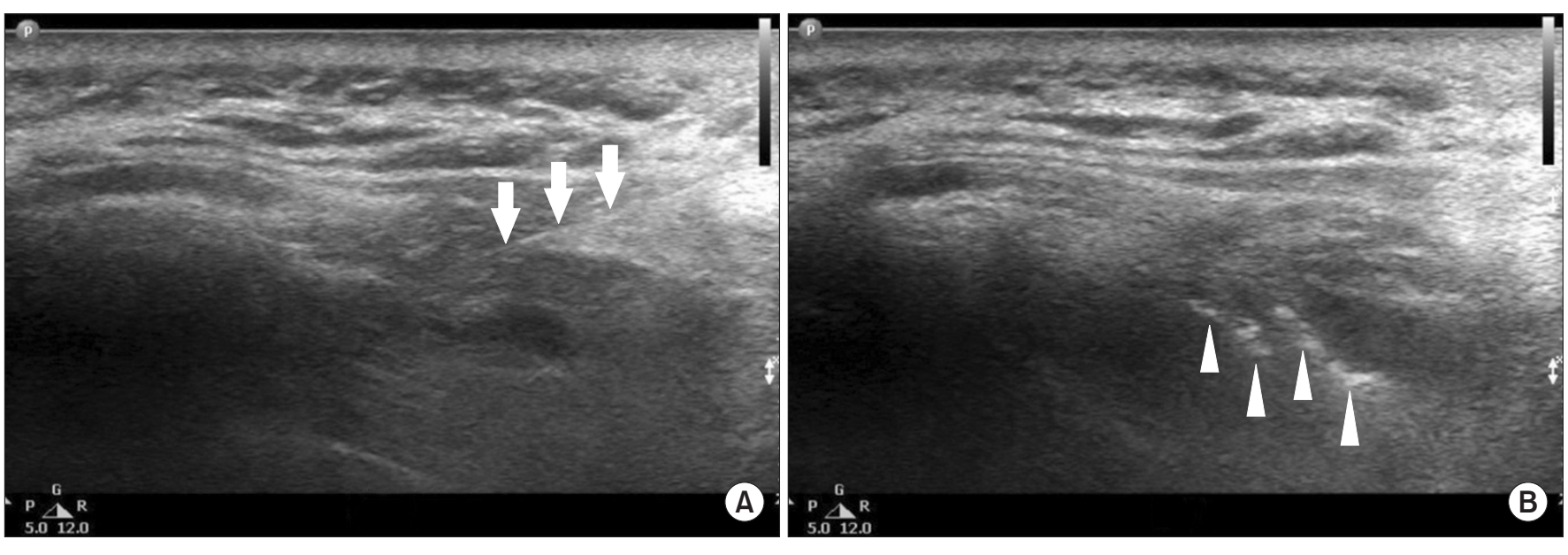

Fig. S1. The ultrasonic images of an occipital nerve block using betamethasone sodium phosphate and ropivacaine$\mathrm{HCl}$ (A, before injection; B, after injection; white arrows, the needle). Crystallized ropivacaine remained in the muscle tissue without dissolution after the injection (white arrow heads). 